\title{
Clinical and Radiological Study of Atticoantral Type of Chronic Suppurative Otitis Media
}

\author{
Ajmath Shaik ${ }^{1}$, Nitin Kumar Kulkarni² ${ }^{2}$ A.V.S. Hanumanthrao ${ }^{3}$ \\ 1, 2, 3 Department of Otorhinolaryngology, Kamineni Academy of Medical Sciences and Research Centre, \\ Hyderabad, Telangana, India.
}

\section{ABSTRACT}

\section{BACKGROUND}

Temporal bone lodges very important structures for hearing and balance. Understanding its anatomy is crucial for surgery plan. Chronic suppurative otitis media is chronic inflammation of the middle ear cleft and it is broadly divided into tubotympanic and atticoantral disease. In atticoantral disease, also known as unsafe Chronic Suppurative Otitis Media (CSOM), the disease process destroys the bones and causes various complications. History and otoscopic examination can clinch the diagnosis but due to prevalence, complications and recurrence of the unsafe CSOM, imaging plays a major role in the management, diagnosis and route map for surgery and anatomical variations which warrants caution during surgery. High-resolution computed tomography (HRCT) provides better resolution, allowing a better understanding of the aetiology, pathology, disease course, and anatomical variations. We aimed to find out clinical and radiological features of atticoantral type of CSOM.

\section{METHODS}

This is a retrospective study which included 78 patients who presented with clinical features of CSOM atticoantral type. The findings and CT (Computed Tomography) scans of temporal bone were analysed. Study was done at the Department of ENT and Head and Neck surgery, Kamineni Academy of Medical Sciences and Research Centre, Hyderabad, from July 2017 to December 2019. The diagnosis of unsafe CSOM was mainly based on history, otoscopic examination and high resolution CT of temporal bone bilaterally with axial and coronal views.

\section{RESULTS}

Atticoantral CSOM is more common in 21 to 30 years age group with male predominance (1.6:1). Ear discharge is seen in $94.8 \%$ of patients and hearing loss is seen in $89.7 \%$ of patients. On otoscopic examination of ear, ear discharge and scutum erosion is seen in $85.8 \%$ and $79.4 \%$ of patients and on HRCT, temporal bone, ossicular erosion (92.3\%) and scutum erosion $(88.4 \%)$ is seen. Incus is the most common ossicle to be affected and is seen in $70.5 \%$ of patients.

\section{CONCLUSIONS}

HRCT temporal bone though is cost effective, it causes more radiation, delineates the details of pathology and extent of the disease and provides information on anatomical variations. It really gives a road map to assist the surgeon during surgery and warns about anatomical pitfalls like high jugular bulb and facial nerve bony dehiscence.

\section{KEY WORDS}

Temporal Bone, Atticoantral CSOM, High Resolution CT Scan, Scutum, Ossicles
Corresponding Author: Dr. Ajmath Shaik, S/O. Hussain, H No, 9-123/B, Dwarakapuri Road no.7, Sathupally Khammam District, Hyderabad, India. E-mail:drazmath007@gmail.com

DOI: $10.14260 / j e m d s / 2020 / 842$

How to Cite This Article: Shaik A, Kulkarni NK, Hanumanthrao AVS. Clinical and radiological study of atticoantral type of chronic suppurative otitis media. J Evolution Med Dent Sci 2020;9(51):3837-3840, 10.14260/jemds/2020/842

Submission 09-06-2020,

Peer Review 26-10-2020,

Acceptance 04-11-2020,

Published 21-12-2020.

Copyright (c) 2020 JEMDS. This is an open access article distributed under Creative Commons Attribution License [Attribution 4.0 International (CC BY 4.0)] 


\section{BACKGROUND}

Chronic suppurative otitis media is a long-standing infection of a part or whole of the middle ear cleft. Middle ear cleft mainly consists of attic, antrum, aditus, middle ear mucosa, mastoid mucosal lining and Eustachian tube. Chronic suppurative otitis media is mainly of two types i.e. tubotympanic and atticoantral. Tubotympanic disease is also called as mucosal type which is associated with mainly disease of Eustachian tube and middle ear; it is associated with less complications. On other hand atticoantral type of CSOM is associated with high number of complications and it also called as squamosal type of disease. Cholesteatoma is associated with atticoantral type of disease. Both type of CSOM cases are required prompt diagnosis and surgical management.

Temporal bone is lodged with hearing and balance organs and its anatomy is very complex. Understanding the anatomy in three dimensional way is crucial for location of pathology and to plan for the surgical route. Due to critical location of the temporal bone, mastoid and middle ear complex; as it is separated from the middle and posterior cranial fossa with a thin bone, infections can have an intracranial extension easily. It has very important facial nerve which is covered by a thin bone. The location of disease from the facial nerve, dural plate, and sinus plate is crucial before commencing the surgery, so here the imaging plays major role in the management and influences the treatment. With the advent of special algorithms like HRCT, it provides an excellent resolution images. ${ }^{1,2}$ CT became a major contribution of the radiology in the otology. We can take ultra-thin sections of various anatomic structures in the temporal bone less than a minute as CT is best for bony defects and it can evaluate soft tissue pathology also.

The most important role of CT scan is it gives information regarding the hidden areas of the middle ear such as sinus tympani and facial recess which are well appreciated in HRCT. ${ }^{3}$

In atticoantral type of CSOM, it involves posterosuperior part of the middle ear cleft (attic, antrum, posterior tympanum and mastoid) and it is associated with cholesteatoma, which because of its bone eroding property causes risk of serious complications. For this reason it is called as unsafe type of CSOM. The atticoantral CSOM is associated with following types of pathological process like cholesteatoma, osteitis, granulation tissue, ossicular necrosis and cholesterol granuloma. Ossicular necrosis is more common in atticoantral disease. Destruction may be limited to long process of incus or it may involve stapes suprastructure and entire ossicular system also. Patient presents with foul smelling ear discharge, hard of hearing, giddiness and headache etc depending upon the severity of the disease. On examination, atticoantral disease has signs like attic perforation retraction pockets, cholesteatoma sacs and scutum erosion. Surgical exploration of mastoid and disease clearance is the main stay of the treatment to reduce or to avoid the complications. Disease process destroys the bones which come in its way such as ear ossicles, bony labyrinth, facial nerve canal, sinus plate, and tegmen tympani. ${ }^{4}$ This bone destruction results in several complications. This retrospective study aimed to find out the frequency, presentation and otoscopic and CT findings of atticoantral type of CSOM.

\section{Objectives}

- $\quad$ To find out the frequency of atticoantral CSOM in different age groups and sex.

- To find out the presentation and otoscopic findings of atticoantral type of CSOM.

- To find out the findings of HRCT of temporal bone in cases of unsafe CSOM.

- To find out the extension of the disease, anatomical variations, and bone erosions of various structures in middle ear and mastoid bone.

\section{METHODS}

This is a retrospective study in which total of 78 cases with chronic suppurative otitis media with atticoantral type are selected and their HRCT scans of temporal bones analysed. These patients were attending the OPD of Department of ENT and Head and Neck surgery at Kamineni Academy of Medical Sciences and Research Centre, Hyderabad, from July 2017 to December 2019. They were selected and analysed retrospectively. The diagnosis of unsafe CSOM was mainly based on history, otoscopic examination and further evaluated with high resolution CT of temporal bone bilaterally with axial and coronal views.

Criterion for inclusion was CSOM with cholesteatoma, granulations, polyp, posterosuperior retraction pockets and marginal perforations or foul-smelling discharge. The patients with a history of previous ear surgery, history suggestive of head injury or skull base trauma in the past or known cases of temporal bone neoplastic pathology were excluded from the study.

The information extracted from the clinical data included age, gender, presenting complaints, duration of symptoms, examination findings, and CT data.

All the HRCT scans were performed at our Kamineni Hospital on the High-Speed Dual Slice Fast Ct Machines. Patients were scanned in axial and coronal axes. $1 \mathrm{~mm}$ thickness sections were studied in both axial and coronal planes. Scanning commenced from the lower margin of the external auditory meatus and extended upward to the arcuate eminence of the superior semi-circular canal as seen on lateral tomogram. Coronal images were obtained perpendicular to the axial plane from the cochlea to the posterior semi-circular canal.

\section{Statistical Analysis}

Statistical analysis was done by chi-square test and statistically significant at 0.05 level.

\section{RESULTS}

\begin{tabular}{|ccc|}
\hline Age Group & Number of Patients & Percentage \\
$11-20$ & 16 & $20.5 \%$ \\
$21-30$ & 24 & $30.7 \%$ \\
$31-40$ & 20 & $25.6 \%$ \\
$41-50$ & 14 & $17.9 \%$ \\
$51-60$ & 4 & $5.1 \%$ \\
\hline \multicolumn{3}{|c|}{ Table 1. Patients Presenting with Different Age Groups } \\
\hline
\end{tabular}


In this study it was found that majority of patients were aged between 21 to 30 years of age. (30.7\%)

And next majority is between 31 to 40 years of age (25.6 $\%)$. Least no of patients are in the age group of $51-60$ years (5.1\%). We operated on a 13 years age male child, who is our youngest patient and 59 years old male with cholesteatoma, who is our eldest patient.

\begin{tabular}{|ccccc|}
\hline Symptom & $\begin{array}{c}\text { No. of } \\
\text { Patients }\end{array}$ & Percentage & $\begin{array}{c}\text { Chi-Square } \\
\text { Value }\end{array}$ & P-Value \\
\hline $\begin{array}{c}\text { Foul smell ear } \\
\text { discharge }\end{array}$ & 74 & $94.80 \%$ & & \\
Hearing loss & 70 & $89.70 \%$ & & \\
Giddiness & 14 & $17.90 \%$ & 186.812 & 0.000 \\
Facial weakness & 2 & $2.50 \%$ & Significant \\
Headache & 18 & $23.00 \%$ & & \\
Swelling behind ear & 4 & $5.10 \%$ & & \\
Ringing sensation & 4 & $5.10 \%$ & \\
\hline Ear pain & 16 & $20.50 \%$ & \\
\hline \multicolumn{4}{r}{ Table 2. Patients Presented with Symptoms } \\
\hline \multicolumn{5}{r}{}
\end{tabular}

In this present study, $94 \%$ patient i.e. 74 patients out of 78 presented to OPD with ear discharge. 70 patients $(89.7 \%)$ presented with hearing loss, 14 patients (17.9) presented with giddiness and 14 patients (23\%) presented with headache. 4 patients had symptoms of swelling behind ear and ringing sensation in ear. Only 2 patients out of $78(2.5 \%)$ presented with facial palsy and 16 patients out of 78 (20.5\%) presented with ear pain.

\begin{tabular}{|ccccc|}
\hline Finding & $\begin{array}{c}\text { No. of } \\
\text { Patients }\end{array}$ & $\begin{array}{c}\text { Percenta } \\
\text { ge }\end{array}$ & $\begin{array}{c}\text { Chi-Square } \\
\text { Value }\end{array}$ & P-Value \\
\hline Discharge & 67 & $85.80 \%$ & & \\
Granulations & 3 & $3.40 \%$ & & \\
Scutum erosion & 62 & $79.40 \%$ & & 0.000 \\
Marginal perforation & 7 & $8.90 \%$ & Significant \\
Attic retraction & 49 & $62.80 \%$ & 144.710 & \\
$\begin{array}{c}\text { Cholesteatoma } \\
\text { Posterosuperior retraction } \\
\text { pocket }\end{array}$ & 25 & $32 \%$ & & \\
Polyp & 26 & $33.30 \%$ & \\
\hline \multicolumn{5}{c}{ Table 3. Otoscopic Findings } \\
\hline
\end{tabular}

Upon otoscopic examination of the ear in OPD; 67 patients out of $78(85 \%)$ have got cleared of the ear discharge in external auditory canal and proceeded for further examination. 62 patients $(79.4 \%)$ have scutum erosion, 3 patients (3.4\%) have granulations in the ear canal, 7 patients (8.9\%) have marginal perforation, 25 patients (32\%) have cholesteatoma flakes over tympanic membrane, 26 patients (33.3\%) have posterosuperior quadrant retraction pocket, 49 patients $(62.8 \%)$ have attic retraction and 9 patients $(11.5 \%)$ presented with fleshy polyp in the external auditory canal.

\begin{tabular}{|ccccc|}
\hline Radiological Finding & $\begin{array}{c}\text { No. of } \\
\text { Patients }\end{array}$ & Percentage & $\begin{array}{c}\text { Chi-Square } \\
\text { Value }\end{array}$ & P Value \\
\hline Scutum erosion & 69 & $88.40 \%$ & & \\
Ossicular chain erosion & 72 & $92.30 \%$ & & \\
Dural plate erosion & 9 & $11.50 \%$ & & 0.000 \\
Sinus plate erosion & 3 & $3.80 \%$ & 180.069 & Significant \\
Facial canal dehiscence & 4 & $5.10 \%$ & & \\
Subperiosteal abscess with & 4 & $5.10 \%$ & & \\
Mastoiditis & 13 & $16.60 \%$ & \\
\hline High jugular bulb & \multicolumn{4}{c}{ Table 4. CT Findings in Temporal Bone } \\
\hline \multicolumn{4}{r}{}
\end{tabular}

Upon further investigation with high resolution CT scan 69 patients out of $78(88.4 \%)$ showed scutum erosion. 72 patients (92.3\%) showed ossicular chain erosion. 9 patients $(11.5 \%)$ have dural plate erosion and 3 patients $(3.8 \%)$ have sinus plate erosion. 4 patients each $(5.1 \%)$ have facial canal dehiscence and subperiosteal abscess and 13 patients (16.6 $\%$ ) have high jugular bulb.

\begin{tabular}{|ccccc|}
\hline Ossicle & $\begin{array}{c}\text { Erosion in No. of } \\
\text { Patient }\end{array}$ & $\%$ & $\begin{array}{c}\text { Chi-Square } \\
\text { value }\end{array}$ & P-Value \\
Malleus & 24 & $30.70 \%$ & & \\
Incus & 55 & $70.50 \%$ & 37.523 & 0.000 Significant \\
Stapes & 9 & $11.50 \%$ & \\
\hline \multicolumn{5}{c}{ Table 5. Ossicle Erosion } \\
\hline
\end{tabular}

Out of 72 patients who presented with ossicular chain erosion, 55 patients have incus erosion and 9 patients have stapes suprastructure erosion and 24 patients have malleus erosion.

\section{DISCUSSION}

In the present study, the youngest patient was 13 years old and the eldest was 59 years old. 24 patients ( $30 \%$ ) were in the age group of $21-30$ years and 20 patients $(30.7 \%)$ in the age group of 31 - 40 years. Studies from other countries shows an average age about 35.1 years as in Paperella and Kim. ${ }^{5}$ This variation is due to greater incidence of CSOM cases in children in our country and they are presenting to hospital in second decade. Male:female ratio was 1.6:1, more in males in accordance with the study done by Vlastarakos et al. ${ }^{6}$

The most common symptom was the foul smelling ear discharge in $94 \%$ cases followed by hearing loss in $89 \%$ cases. Tinnitus, vertigo, and facial nerve palsy were low in the present series. This probably indicates that the patients come to hospital relatively early before any intracranial and temporal complication and are presented for initial treatment

In the study by Glascocketal ${ }^{4}$ he noted majority of symptoms are ear discharge and hearing loss. Thukral CL Singh et $\mathrm{al}^{7}$ in their study they noted majority of the symptoms are hearing loss and ear discharge; our study correlated well with their study.

All cases in this study presented with foul smelling discharge which clinches the diagnosis of atticoantral type of CSOM. Most of the cases are diagnosed on the basis of history and otoscopic examination. Findings in the otoscopy with clinical history made route towards the diagnosis of atticoantral CSOM. On examination with otoscope, majority of patients, (85\%) have ear discharge in external auditory canal which was cleaned and proceeded for the further examination.

in the present study 62 patients $(79.4 \%)$ have scutum erosion, 3 patients (3.4\%) have granulations in the ear canal and 7 patients (8.9\%) have marginal perforation. 25 (32\%) have cholesteatoma flakes over tympanic membrane. 26 patients (33.3\%) have posterosuperior quadrant retraction pocket. 49 patients $(62.8 \%)$ have attic retraction. 9 patients (11.5\%) presented with fleshy polyp in the external auditory canal. In the study Shreeya V Kulkarni et al ${ }^{8}$ stated that out of 100 cases they noted $40(40 \%)$ cases showed perforation, cholesteatoma in 59 (59\%) cases, granulations in (2\%) cases and polyp in $6(6 \%)$ cases.

Unsafe CSOM is diagnosed generally by otologic examination and can be demonstrated by computerized tomography which shows a soft tissue mass with characteristic ossicular changes and erosion of bone. 
Cholesteatoma in hidden areas, like posterior tympanic recess, revealed with a CT scan even though it is not detected by otologic examination.

Upon investigation with high resolution CT scan of the temporal bone, 69 patients out of 78 have scutum erosion and 72 patients ( $92 \%$ ) have ossicular erosion. 9 patients $(11.5 \%)$ have dural plate erosion and 3 patients (3.8\%) have sinus plate erosion. 4 patients each $(5.1 \%)$ have facial canal dehiscence and subperiosteal abscess. In this study, mastoiditis complicated with subperiosteal abscess was found in $5.1 \%$ cases of COM. This is similar to findings by Leskinen and Jero et $\mathrm{al}^{9}$ who found it, in $7 \%$ cases and 13 patients $(16.6$ $\%$ ) have high jugular bulb. The high jugular bulb incidence is high in studies with Zelikovich et $\mathrm{al}^{8}$ (36.5\%) and low in studies with Tomura et al ${ }^{10}(1.6 \%)$.

In another study, done by Vinit Kumar Sharma et al ${ }^{11}$ radiological changes in unsafe CSOM of temporal bone; they noted 50 cases of scutum erosion in $84 \%$ cases and ossicular erosion in $90 \%$ cases. The present study correlated well with this study. Ossicular chain erosion was present in 72 out of 78 (92.3\%) cases which it is correlated with Mafee et al. ${ }^{12}$ Garber and Dort ${ }^{13}$ and Jackler et al. ${ }^{14}$ detected ossicular destruction in 54 of 60 patients. In the present study, investigation with CT scanning showing most commonly eroded ossicle is incus which is affected in 55 cases $(70 \%)$. Jackler et al. ${ }^{14}$ also reported similar finding.

\section{CONCLUSIONS}

Most of the patients with unsafe CSOM present with chief complaints of ear discharge and hard of hearing. Unsafe CSOM is more common in third decades with higher incidence in males (1.6 times). Scutum erosion and ossicular erosion are the most common findings.

The present study clearly identifies the symptoms of unsafe CSOM and its otoscopic findings. HRCT temporal bone though is cost effective, it causes more radiation, delineates the details of pathology and extent of the disease and provides information on anatomical variations. It really gives a road map to assist the surgeon during surgery and warns about anatomical pitfalls like high jugular bulb and facial nerve bony dehiscence.

Data sharing statement provided by the authors is available with the full text of this article at jemds.com.

Financial or other competing interests: None.

Disclosure forms provided by the authors are available with the full text of this article at jemds.com.

\section{REFERENCES}

[1] Bagul M. High-resolution computed tomography study of temporal bone pathologies. Headache 2016;32(1):26-66.

[2] Kumaresan S, Nirmala M. Usefulness of pre-operative high-resolution computed tomography in middle ear cholesteatoma. International Journal of Scientific Study 2017;5(5):248-51.

[3] Sreedhar S, Pujary K, Agarwal AC, et al. Role of highresolution computed tomography scan in the evaluation of cholesteatoma: a correlation of highresolution computed tomography with intra-operative findings. Indian Journal of Otology 2015;21(2):103-6.

[4] Glasscock ME 3rd, Dickins JR, Wiet R. Cholesteatoma in children. Laryngoscope 1981;91(10):1743-53.

[5] Paparella MM, Kim CS. Mastoidectomy update. Laryngoscope 1977;87(12):1977-88.

[6] Vlastarakos PV, Kiprouli C, Pappas S, et al. CT scan versus surgery: how reliable is the preoperative radiological assessment in patients with chronic otitis media? Eur Arch Otorhinolaryngol 2012;269(1):81-6.

[7] Thukral CL, Singh A, Singh S, et al. Role of high resolution computed tomography in evaluation of pathologies of temporal bone. J Clin Diagn Res 2015;9(9):TC07-TC10.

[8] Kulkarni SV, Bhagat MB, Burse KS, et al. A Study of correlation between clinical features, radiological and operative findings in safe and unsafe CSOM. MVP Journal of Medical Sciences 2019;6(1):1-7.

[9] Leskinen K, Jero J. Acute complications of otitis media in adults. Clinical Otolaryngol 2005;30(6):511-6.

[10] Tomura N, Sashi R, Kobayashi M, et al. Normal variations of the temporal bone on high resolution CT: their incidence and clinical significance. Clin Radiol 1995;50(3):144-8.

[11] Sharma VK, Prajapati N, Sharma R, et al. Radiological changes in anatomy of temporal bone in cases of unsafe chronic suppurative otitis media: a retrospective study. Indian J Otol 2017;23(3):176-9.

[12] Mafee MF, Kumar A, Yannias DA, et al. Computed tomography of the middle ear in the evaluation of cholesteatomas and other soft-tissue masses: comparison with pluridirectional tomography. Radiology 1983;148(2):465-72.

[13] Garber LZ, Dort JC. Cholesteatoma: diagnosis and staging by CT scan. J Otolaryngol 1994;23(2):121-4.

[14] Jackler RK, Dillon WP, Schindler RA. Computed tomography in suppurative ear disease: a correlation of surgical and radiographic findings. Laryngoscope 1984;94(6):746-52. 